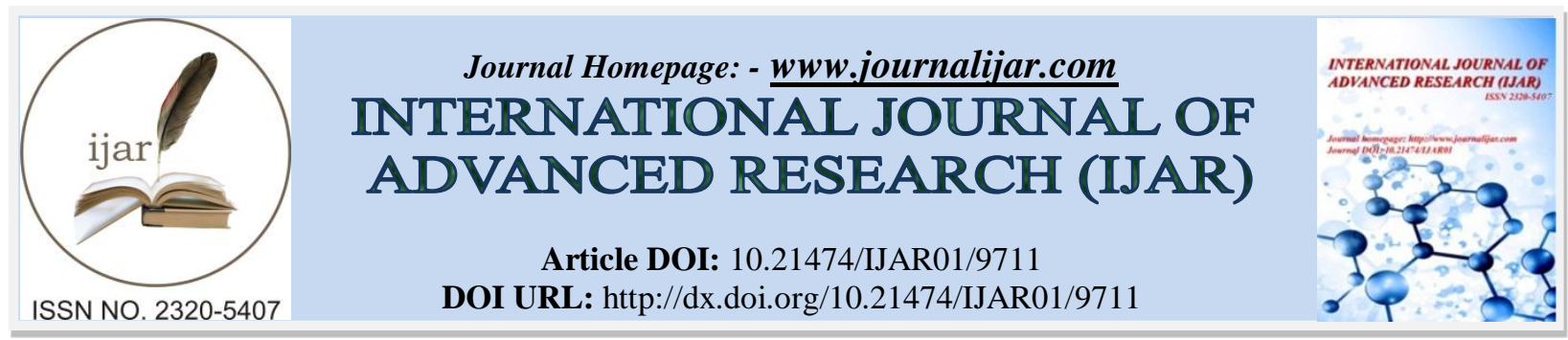

RESEARCH ARTICLE

\title{
EFFECT OF ALUMINUM OXIDE ADDITION ON COMPRESSIVE STRENGTH, MICROHARDNESS AND SETTING EXPANSION OF DENTAL PLASTER.
}

\begin{abstract}
Tamer M. Hamdy.
Restorative and Dental Materials Department, National Research Centre (NRC), El Bohouth St., 12622 Dokki, Giza, Egypt.
\end{abstract}

\section{Manuscript Info}

Manuscript History

Received: 08 July 2019

Final Accepted: 10 August 2019

Published: September 2019

\section{Key words:-}

Dental plaster, gypsum products, aluminum oxide, models, dies, casts, compressive strength, microhardness, dimensional changes.

\section{Abstract}

Introduction: Gypsum products are widely used in clinical dentistry for construction of dental models (casts) and dies. The ideal requirement of model and die materials include a high compressive strength and resistance to abrasion, in addition to high dimensional stability. Dental plaster, stone, and improved stone are the three types of gypsum products used in dentistry differ in their physical and mechanical characteristics. Although dental plaster is considered as the least expensive of the three gypsum products, but their low strength, microhardness and dimensional stability limit their use as mater cast and die materials.

Aim: The aim of this study was to evaluate the effect of addition of 15 weight $\%$ aluminum oxide fillers on compressive strength, microhardness and setting expansion of the dental plaster.

Materials and Methods: A total of 60 specimens; 30 specimens per each group were prepared. The control group was made by mixing dental plaster with water. The other group was made by addition of 15 wt.\% aluminum oxide fillers to the conventional dental plaster prior to mixing with water. Water-powder was done according to the manufacturer's recommendations among all groups. After 24 hours compressive strength, surface microhardness and setting expansion were evaluated by Universal testing machine; Vickers microhardness testing and extensometer respectively.

Results: Dental plaster reinforced by $15 \mathrm{wt} . \%$ aluminum oxide fillers demonstrated higher mean compressive strength and microhardness values, while lower mean setting expansion values compared to that of conventional dental plaster $(\mathrm{p}<0.05)$.

Conclusion: Dental plaster reinforced by 15 wt. $\%$ aluminum oxide fillers could be used alternatively to type IV: high strength dental stone (improved stone) to be used as master cast and die materials.

Copy Right, IJAR, 2019,. All rights reserved.

\section{Introduction:-}

Gypsum is naturally occurring minerals, is considered as one of the most frequently used dental materials. Chemically they are calcium sulfate dihydrate. According to American Dental Association (ADA), gypsum products are classified into five types [1]; Type I: impression plaster, Type II: dental plaster, Type III: dental stone, Type IV:

Corresponding Author:-Tamer M. Hamdy.

Address:- National Research Centre (NRC), El Bohouth St., 12622 Dokki, Giza, Egypt. 
high strength dental stone and Type V: high strength and high expansion dental stone. All these gypsum products are chemically the same but display difference in their physical and mechanical properties[2].

There are various applications for gypsum products in dentistry for fabrication of fixed prosthesis, partial and complete dental appliance. These include fabrication of preliminary study casts (models) and master casts. In addition to, dies fabrication for single dental restoration construction. Selection of gypsum product types depends on their use[3].The ideal requirement of gypsum products to be used as model and/or die materials include; a high compressive strength to withstand carving force and high surface hardness to resist scratching upon manipulation, in addition to minimum dimensional changes (setting expansion) which affect the fitting and accuracy of the prepared dental prosthesis, easily manipulation and being inexpensive[4]. Although dental plaster is cheap and easily manipulated, they have a great shortcomings comprises low compressive strength, easily abrasion and dimensional instability[5].

There is urgent demand for enhanced materials with improved properties to replace existing conventional materials. The physical and mechanical properties of the gypsum products could be improved by addition of some chemicals to the traditional formula[6]. Numerous attempts were done to improve the compressive strength and microhardness of the die materials. These attempts are primarily aimed at to reduce the amount of the required water or by adding reinforcing additives such as calcium oxide and calcium carbonate [7]. Aluminum oxide is a commonly naturally occurring ceramic oxides, which are extensively used in dentistry as reinforcement fillers that can raise the mechanical properties and surface microhardness of their composite[8]. It was observed that incorporation of 15 wt.\% aluminum oxide powder to heat cure denture base resin increased both their compressive strength and microhardness[9].Therefore, the purpose of the present study is to evaluate the effects of addition of 15 wt.\% aluminum oxide fillers to dental plaster to optimize their properties regarding compressive strength, microhardness and setting expansion extending their dental applications.

\section{Materials and Methods:-}

A total of 60 specimens; 30 specimens per each group were prepared in this in vitro study ( $\mathrm{n}=10)$. The control group was made by mixing dental plaster (Garreco dental plaster, USA) with water. The other group was reinforced by addition of 15 wt.\% aluminum oxide fillers (SDFCL Sd Fine Chem Limited, Chennai, Tamil Nadu, India) to the previously mentioned conventional dental plaster prior to mixing with water. Water-powder ratio was done following the manufacturer's recommendations among all groups. Gypsum products and water were mixed mechanically under vibrator (Plaster vibrator, Technoflux, USA) for 20 seconds to reach a smoothed homogeneous mix, avoiding air bubbles. The mix was poured into the previously prepared special molds. After 24 hours, specimens were evaluated for both compressive strength and microhardness tests.

A split metal mold (20 mm diameter and $40 \mathrm{~mm}$ height) was used to prepare specimens for compressive strength measurement according to ANSI/ADA no.25 (Fig 1)[1]. Compressive strength was evaluated using a universal testing machine (Shimadzu Autograph AG-X plus $5 \mathrm{kN}$, Kyoto, Japan) at crosshead speed of $1 \mathrm{~mm} / \mathrm{min}$. with load cell $5 \mathrm{KN}$. The results were obtained in kilogram force (kgf).

Microhardness testing was done by preparing specimens according to ADA specification No.25 measuring (40 mm in diameter and $10 \mathrm{~mm}$ in height)[1]. Vickers microhardness values were determined by application of 30 gram load for 30 seconds to specimens using a digital hardness tester (Fig 2).

The dimensional change (setting expansion) was evaluated by an extensometer with dial device (Plaster extensometer for gypsum, Novanna, UK). The metal matrices used to make the specimens had a movable piece attached at the end, where the active tip of the micrometer touched. The dial of the micrometer was set on zero and the matrix was positioned against the wall (Fig 3). When any change in the volume of the gypsum occurred, the micrometer showed this change in millimeter $(\mathrm{mm})$. The expansion was analyzed at 2 hours after gypsum mixing; dimensional change measured in $\mathrm{mm}$, setting expansion expressed as a percentage. Later on, the specimen was separated from the matrix[10].

Statistical analysis was performed using Statistical Package for the Social Sciences (SPSS Inc., IBM Corporation; USA). The data were subjected to Independent sample T-test to compare mean values of compressive strength between two groups (conventional dental plaster and reinforced dental plaster). The significance level was set at $\mathrm{P} \leq$ 0.05. Similarly, the same test was used to compare results of microhardness as well as setting expansion between the two groups. 


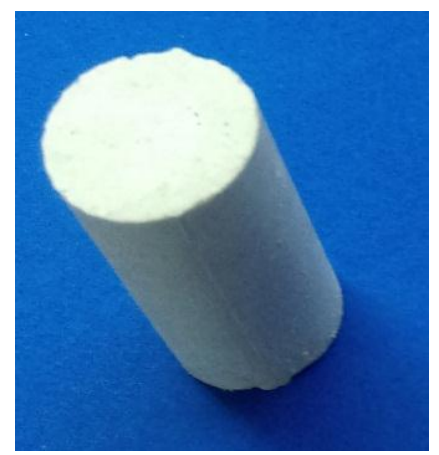

Fig 1:- Cylindrical specimen to test the compressive strength.

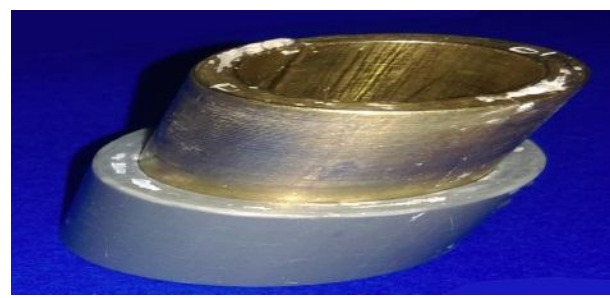

Fig 2:-Microhardness test mold.

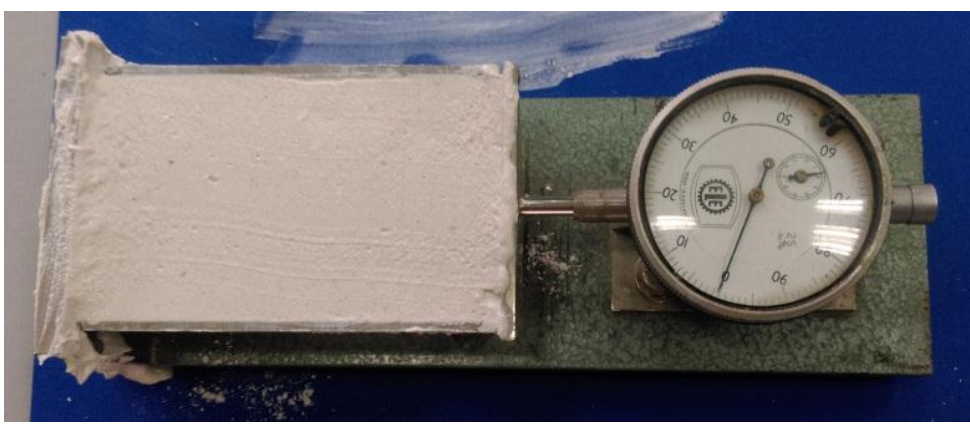

Fig 3:- extensometer with dial device.

\section{Results:-}

There was significant difference between the results of the two groups; conventional and reinforced dental plaster in all the tests performed in this study $(\mathrm{p}<0.05)$. The reinforced dental plaster showed higher mean compressive strength and microhardness values, while mean lower setting expansion values compared to that of conventional dental plaster as shown in Table (1) and (Fig 4-6).

Table 1:- The mean, standard deviation values and results of Independent sample T-test for comparison between compressive strength, microhardness and setting expansion of the two groups.

\begin{tabular}{|l|l|l|l|}
\hline Mean Groups & $\begin{array}{l}\text { Conventional dental } \\
\text { plaster }\end{array}$ & $\begin{array}{l}\text { Reinforced dental } \\
\text { plaster }\end{array}$ & P value \\
\hline Compressive strength (kgf) & $822.3 \pm 35.3$ & $1380.2 \pm 43$ & $\leq 0.001^{*}$ \\
\hline Microhardness (VHN) & $63.5 \pm 5.1$ & $114.3 \pm 6.8$ & $\leq 0.001^{*}$ \\
\hline Setting expansion (\%) & $0.12 \pm 0.01$ & $0.07 \pm 0.01$ & $\leq 0.001^{*}$ \\
\hline
\end{tabular}

Mean with different letters indicate statistically significance difference, *: significant $(\mathrm{p}<0.05)$. 


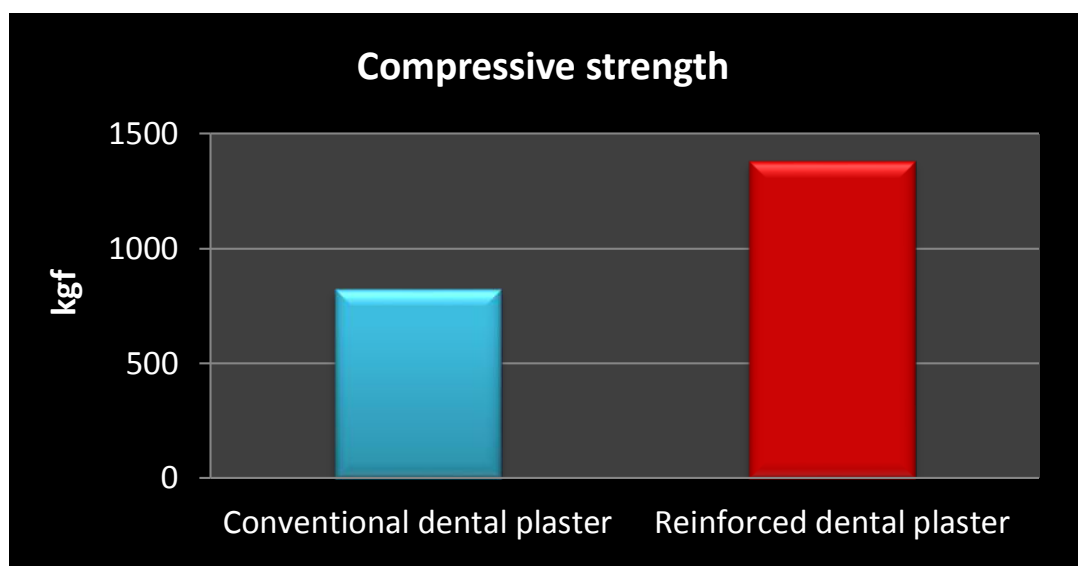

Fig 4:-Histogram showing mean compressive strength (kgf) between the two groups.

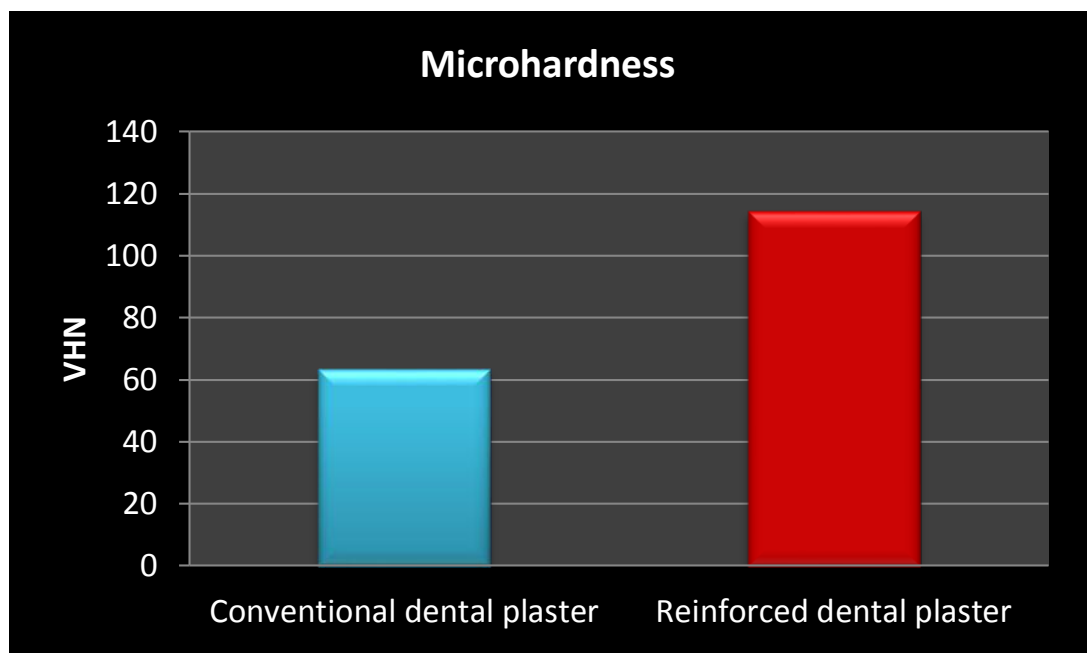

Fig 5:-Histogram showing mean Vicker microhardness number (VHN) between the two groups.

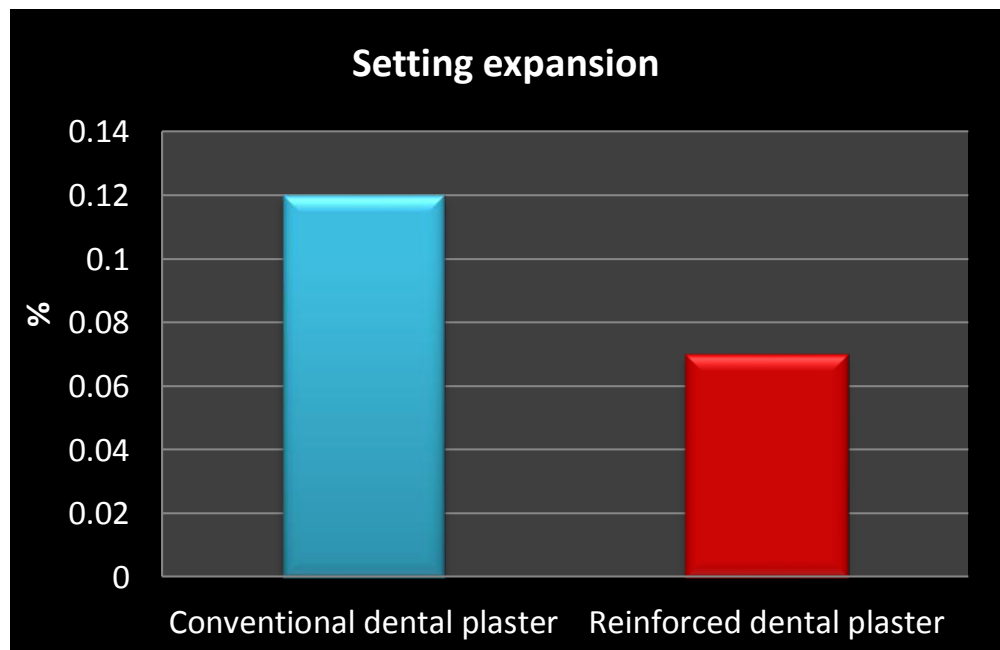

\section{Discussion:-}

Fig 6:-Histogram showing mean setting expansion (\%) between the two groups.

Gypsum products are used in dentistry for positive reproductions of oral hard and soft structures. These replicas are termed casts, models or dies. Dies are widely used in the production of cast restorations. Both strength, resistance to abrasion and dimensional stability is very much crucial parameters for the successful fabrication of accurate wax pattern and consequently dental restoration[3].The crystal number and their entanglement prominently contribute to 
the final strength, surface microhardness and dimensional stability of the set gypsum material. Any factor which may alters these parameters or interferes with the crystals growth will affect their strength and abrasion resistance[7].

During mixing of calcium sulfate hemihydrate and water, gypsum products undergo setting and exhibit dimensional changes. This dimensional change mainly is due to growth in size and number of dihydrate crystals. As they grow, crystals entanglements occurs and push against each other, give rise to what is called "outward thrust action". These crystals will occupy a larger space volume, thereby causing an expansion. Moreover, this outward thrust action causes an internal porosity in the set mass[11].

Gypsum product materials used for construction of master casts and dies should possess high mechanical properties and resistance to scratching in order to withstand the force during laboratory fabrication and construction of wax pattern which in turn converted to final dental restorations. Moreover the linear expansion of gypsum products during the change from hemihydrate to dihydrate should be kept minimal, to avoid prosthesis misfit[6]. Several studies have been conducted to improve gypsum products mechanical properties. The incorporation of different additives such as silica and glass fibers could reduce the amount of used gypsum powder (calcium sulfate hemihydrate) during mixing leading to improvement in their mechanical properties of gypsum products[6].

Aluminum oxide $\left(\mathrm{Al}_{2} \mathrm{O}_{3}\right)$ is chemically inert ceramic, white in color and relatively non-toxic. Thus, it serves as filler into different dental materials. They have a great ability to improve the compressive strength and surface microhardness by acting as reinforcing agent[12].

In this study, the reinforced dental plaster with $15 \mathrm{wt} \%$ aluminum oxide fillers showed higher mean compressive strength and microhardness values compared to that of conventional dental plaster groups. This might be attributed to the strengthening effect of strong and hard aluminum oxide ceramic fillers. Moreover the reduced percentage of gypsum products on expense of aluminum oxide filler addition on the reinforced groups will lead to decrease in the produced dihydrate crystals. Thus, decrease in the outward thrust action. Subsequently decrease the formation of internal porosity in the set materials.

Moreover, the reinforced dental plaster with $15 \mathrm{wt} \%$ aluminum oxide fillers showed mean lower setting expansion values compared to that of conventional dental plaster groups. This might be attributed to the lower percentage of gypsum products on expense of aluminum oxide fillers on the reinforced groups which may decrease the amount of produced dihydrate crystals and thus decrease the effect of outward thrust action of the growing crystals and hence reduce the linear expansion of the set materials.

The compressive strength values of the reinforced dental plaster with $15 \mathrm{wt} \%$ aluminum oxide fillers exceed the minimum requirements of (35 $\mathrm{MPa})$ and lower than the maximum acceptable range of setting expansion (0.0-0.15 $\%$ ) determined by American Dental Association Specification No. 25 and ISO standard 6873: 1998 for (type IV: high strength dental stone)[1][13].

\section{Conclusion:-}

Dental plaster reinforced by 15 wt.\% aluminum oxide fillers could be used alternatively to type IV: high strength dental stone (improved stone) to be used as master cast and die materials.

\section{References:-}

1. Proposed addendum to ANSI/ADA specification no. 25 for dental gypsum products. J Am Dent Assoc 1985; 111: 1003.

2. Darvell BW. Chapter 2 - Gypsum Materials. In: Materials Science for Dentistry (Tenth Edition), pp. 40-69.

3. Abdelaziz KM, Combe EC, Hodges JS. The effect of disinfectants on the properties of dental gypsum, part 2: Surface properties. J Prosthodont 2002; 11: 234-240.

4. Kenyon BJ, Hagge MS, Leknius C, et al. Dimensional accuracy of 7 die materials. J Prosthodont 2005; 14: 2531.

5. Subhan Rao, Pervaiz K, Malik S CZ. the Effect of Diverse Water Type on the Water Powder Ratio of Various Dental. Pakistan Oral Dent J 2016; 36: 331-335. 
6. Razak WA, Yassin IN, Kati FA. Effect of Adding some Additives and Drying Method on Compressive Strength of Gypsum Products. Tikrit J Dent Sci 2017; 5: 25-32.

7. Jayaprakash K, Upadhya P, Nandish B, et al. Impact of Water Quality and Water Powder Ratio on the Properties of Type 4 - Die Stones (Gypsum Products) used in Dentistry. Int J Heal Rehabil Sci 2014; 3: 75.

8. Karlina E, Susra S, Fatmala Y, et al. Morphological characterization of ceramic fillers made from Indonesian natural sand as restorative dental materials. In: AIP Conference Proceedings. 2018. Epub ahead of print 2018. DOI: $10.1063 / 1.5021224$.

9. Lavanya D. Effects of Addition of Aluminum Oxide on Flexural Strength and Hardness of Acrylic Resins. IOSR J Dent Med Sci 2017; 6: 01-06.

10. dos Santos Proença J, Suzuki MM, da Costa SC, et al. Influence of different water types on the physical and mechanical properties of gypsum. Brazilian J Oral Sci 2015; 14: 199-203.

11. Michalakis KX, Asar NV, Kapsampeli V, et al. Delayed linear dimensional changes of five high strength gypsum products used for the fabrication of definitive casts. J Prosthet Dent 2012; 108: 189-195.

12. Alhareb AO, Akil HM, Ahmad ZA. Impact strength, fracture toughness and hardness improvement of PMMA denture base through addition of nitrile rubber/ceramic fillers. Saudi J Dent Res 2017; 8: 26-34.

13. ISO. Iso 6873:1998 - Dental gypsum products. 1998. 